\title{
Single organ metastatic disease and local disease status, prognostic factors for overall survival in stage IV non-small cell lung cancer: Results from a population-based study
}

Citation for published version (APA):

Hendriks, L. E., Derks, J. L., Postmus, P. E., Damhuis, R. A., Houben, R. M. A., Troost, E. G. C., Hochstenbag, M. M., Smit, E. F., \& Dingemans, A. -M. C. (2015). Single organ metastatic disease and local disease status, prognostic factors for overall survival in stage IV non-small cell lung cancer: Results from a population-based study. European Journal of Cancer, 51(17), 2534-2544.

https://doi.org/10.1016/j.ejca.2015.08.008

Document status and date:

Published: 01/11/2015

DOI:

10.1016/j.ejca.2015.08.008

Document Version:

Publisher's PDF, also known as Version of record

Document license:

Taverne

Please check the document version of this publication:

- A submitted manuscript is the version of the article upon submission and before peer-review. There can be important differences between the submitted version and the official published version of record. People interested in the research are advised to contact the author for the final version of the publication, or visit the DOI to the publisher's website.

- The final author version and the galley proof are versions of the publication after peer review.

- The final published version features the final layout of the paper including the volume, issue and page numbers.

Link to publication

\footnotetext{
General rights rights.

- You may freely distribute the URL identifying the publication in the public portal. please follow below link for the End User Agreement:

www.umlib.nl/taverne-license

Take down policy

If you believe that this document breaches copyright please contact us at:

repository@maastrichtuniversity.nl

providing details and we will investigate your claim.
}

Copyright and moral rights for the publications made accessible in the public portal are retained by the authors and/or other copyright owners and it is a condition of accessing publications that users recognise and abide by the legal requirements associated with these

- Users may download and print one copy of any publication from the public portal for the purpose of private study or research.

- You may not further distribute the material or use it for any profit-making activity or commercial gain

If the publication is distributed under the terms of Article 25fa of the Dutch Copyright Act, indicated by the "Taverne" license above, 


\title{
Single organ metastatic disease and local disease status, prognostic factors for overall survival in stage IV non-small cell lung cancer: Results from a population- based study
}

\author{
L.E. Hendriks $^{\mathrm{a}, *, 1}$, J.L. Derks ${ }^{\mathrm{a}, 1}$, P.E. Postmus ${ }^{\mathrm{b}}$, R.A. Damhuis ${ }^{\mathrm{c}}$, R.M.A. Houben ${ }^{\mathrm{d}}$, \\ E.G.C. Troost ${ }^{\mathrm{e}}$, M.M. Hochstenbag ${ }^{\mathrm{a}}$, E.F. Smit ${ }^{\mathrm{f}}$, A.-M.C. Dingemans ${ }^{\mathrm{a}}$
}

\footnotetext{
${ }^{\text {a }}$ Department of Pulmonary Diseases, GROW-School for Oncology and Developmental Biology, Maastricht University Medical Center+, Maastricht, The Netherlands

${ }^{\mathrm{b}}$ Department of Pulmonary Diseases, Clatterbridge Cancer Centre, Liverpool Heart \& Chest Hospital, University of Liverpool, Liverpool, UK

${ }^{\mathrm{c}}$ Department of Registry and Research, Comprehensive Cancer Centre the Netherlands, Rotterdam, The Netherlands

${ }^{\mathrm{d}}$ Department of Radiation Oncology (MAASTRO Clinic), GROW-School for Oncology and Developmental Biology,

Maastricht University Medical Center+, Maastricht, The Netherlands

${ }^{\mathrm{e}}$ Department of Radiation Oncology, University Hospital and Medical Faculty Carl Gustav Carus of TU Dresden, Fetscherstr. 74, 01307 Dresden, Germany

${ }^{\mathrm{f}}$ Department of Thoracic Oncology, The Netherlands Cancer Institute, Amsterdam, The Netherlands
}

Received 8 May 2015; received in revised form 3 July 2015; accepted 10 August 2015

Available online 28 August 2015

\section{KEYWORDS \\ Non-small cell lung \\ cancer \\ Stage IV \\ Prognosis \\ Metastases \\ Local disease status}

\begin{abstract}
Purpose: To analyse the prognostic impact on overall survival (OS) of single versus multiple organ metastases, organ affected, and local disease status in a population based stage IV non-small cell lung cancer (NSCLC) cohort.

Methods: In this observational study, data were analysed of all histologically confirmed stage IV NSCLC patients diagnosed between 1 January 2006 and 31 December 2012 registered in the Netherlands Cancer Registry. Location of metastases before treatment was registered. Multivariable survival analyses [age, gender, histology, M-status, local disease status, number
\end{abstract}

\footnotetext{
Abstract presented as poster discussion at the European Lung Cancer Conference (ELCC), 15-18 April 2015.

* Corresponding author at: Dept. of Pulmonary Diseases, Maastricht University Medical Center+, PO Box 5800, 6202 AZ Maastricht, The Netherlands. Tel.: +31 (0)433871318; fax: +31 (0)433875051.

E-mail addresses: Lizza.hendriks@mumc.nl (L.E. Hendriks), j.derks@maastrichtuniversity.nl (J.L. Derks), pepostmus@gmail.com (P.E. Postmus), R.Damhuis@iknl.nl (R.A. Damhuis), Ruud.houben@maastro.nl (R.M.A. Houben), Esther.Troost@uniklinikum-dresden.de (E.G.C. Troost), m.hochstenbag@mumc.nl (M.M. Hochstenbag), E.smit@nki.nl (E.F. Smit), a.dingemans@mumc.nl (A.-M.C. Dingemans).

${ }^{1}$ The first two authors contributed equally to the manuscript.
} 
of involved organs, actual organ affected] were performed for all patients and for an

${ }^{18}$ fluorodeoxyglucose-positron emission tomography $\left({ }^{18}\right.$ FDG-PET)-staged subgroup.

Results: 11,094 patients were selected: $60 \%$ male, mean age 65 years, $73 \%$ adenocarcinoma. Median OS for $1(N=5676), 2(N=3280)$, and $\geqslant 3(N=2138)$ metastatically affected organs was $6.7,4.3,2.8$ months, respectively $(p<0.001)$. Hazard ratio (HR) for 2 versus 1 organ $(\mathrm{s})$ was $1.33(p<0.001)$, for $\geqslant 3$ versus 1 organ(s) $1.91(p<0.001)$. Results were confirmed in the ${ }^{18}$ FDG-PET-staged cohort $(N=1517)$ : patients with single organ versus 2 and $\geqslant 3$ organ metastases had higher OS $(8.6,5.7,3.8$ months, HR 1.40 and 2.17 , respectively, $p<0.001)$. In single organ metastases, OS for low versus high TN-status was 8.5 versus 6.5 months [HR $1.40(p<0.001)$ ]. ${ }^{18}$ FDG-PET-staged single organ metastases patients with low TNstatus had a superior OS than those with high TN-status (11.6 versus 8.2 months, HR 1.62, $p<0.001)$.

Conclusion: Patients with single organ metastases stage IV NSCLC have a favourable prognosis, especially in combination with low TN status. They have to be regarded as a separate subgroup of stage IV disease.

(C) 2015 Elsevier Ltd. All rights reserved.

\section{Introduction}

The tumour, node and metastasis (TNM) classification of non-small cell lung cancer (NSCLC) is a prognostic tool to stratify patients. The current 7 th edition is based on an analysis of a retrospective worldwide database of more than 100,000 cases including data from clinical trials, consortium/surgical series and registry-series $[1,2]$. Currently, within stage IV two prognostically different subgroups are distinguished; M1a (intrathoracic: pleural and/or pericardial dissemination and/or metastasis to contralateral lung) and M1b (distant metastasis), with median overall survival (OS) of 8 and 6 months, respectively [1,2]. In the M1b group $(N=4350)$, median OS was slightly worse for patients with multiple distant metastatic sites compared to a single site. No OS difference regarding the actual organ affected was encountered in the single organ metastases subgroup $(N=2480)$; it was not possible to analyse the impact of single versus multiple sites in a specific organ [2]. Currently, there is a lack of data gathered in routine clinical practice regarding the prognostic value of the extent of metastases in population based stage IV NSCLC cohorts and it is not clear whether results are comparable for ${ }^{18}$ fluorodeoxyglucose-positron emission tomography $\left({ }^{18}\right.$ FDG-PET)-staged patients, due to possible upstaging [3].

The Netherlands Cancer Registry (NCR) has registered all patients diagnosed with cancer in the Netherlands since 1989 and has $98 \%$ nationwide coverage. In contrast to TNM7, metastatic sites at time of NSCLC diagnosis are standardly recorded according to clinical data [4]. Here, we analysed the prognostic impact of single versus multiple organs with metastases, local disease status and impact of the actual organ affected in stage IV NSCLC.

\section{Materials and methods}

\subsection{Patient selection: $N C R$}

All patients diagnosed between 1 January 2006 and 31 December 2012 with NSCLC (adenocarcinoma (AdC) and squamous cell carcinoma (SqCC)) were selected. Only histology was selected to avoid cytological classification bias. Large cell carcinoma (LCC) was not selected because of recent evidence separating $80 \%$ of LCC into $\mathrm{AdC} / \mathrm{SqCC}$, possibly introducing classification bias [5]. Data retrieval was on 21 March 2014.

Data have been actively collected by data managers according to standardised formats and have been linked to the Dutch Pathology Registry and National Civil Registry for follow-up and histology confirmation [4]. Information includes: gender; age; diagnosis year; morphology code; stage (until 2009 TNM6, $\geqslant 2010$ TNM7); first-line treatment; diagnosis of previous malignancy and metastases localisation at diagnosis. Metastases sites are recorded according to documented clinical data with maximal three separate locations. In cases with more than three locations, the first two are recorded and the last is coded as $\geqslant 3$ metastases. Organ count is irrespective of the number of metastases within this organ. Reporting of staging procedures as ${ }^{18}$ FDG-PET or magnetic resonance imaging (MRI) brain is not mandatory.

Excluded were: no TNM recorded, previous malignancy within five years of NSCLC, metachronous NSCLC, stage IV NSCLC according to TNM6 solely based on pulmonary metastases (possibly TNM7 T4, i.e. no stage IV), no metastases sites documentation, and no Civil Registry linkage.

Subgroup analyses were performed in patients in whom an ${ }^{18}$ FDG-PET-scan was documented to investigate upstaging effects [3]. Separate subgroup analyses 
were performed for TNM6 and TNM7 when required, as some changes in TNM7 T-classification occurred. To analyse impact of anticancer treatment an exploratory analysis was performed in patients receiving active anticancer treatments as opposed to best supportive care (BSC) only. Palliative radiotherapy without systemic treatment was classified as BSC. Study approval was by the NCR data monitoring committee and procedures were performed according to national privacy regulations.

\subsection{Statistical analysis}

Statistical analysis was conducted with SPSS (v20; SPSS Inc., Chicago, IL). OS was calculated from day of diagnosis till death and analysed according to the Kaplan-Meier method and tested for significance with log-rank test. Patients who were alive at closing date (31 December 2012) or who were lost-to-follow-up were censored at last date of follow-up. A multivariate Cox regression model was constructed including covariates that were found significant in univariate analyses. Covariates tested were: age, gender, histology, TNM7 M1b versus M1a and TNM6 M1, low TN-stage versus high TN-stage (i.e. T1-2 and N0-1 versus T3-4 and/or N2-3), number of organs with metastases (i.e. 1, 2 or $\geqslant 3$ ) and within single organ metastases also actual organ affected. Proportional hazard assumption was tested using visual inspection of $\log$ (minus Log) survival plots. Continuous variables were compared with the Mann Whitney $U$-test; categorical data were tested according to the chi-square test. $P$ values of $\leqslant 0.05$ for two-sided tests were considered statistically significant.

\section{Results}

\subsection{Patient characteristics}

Between 01 January 2006 and 31 December 2012, 11,094 stage IV patients were eligible for analysis (CONSORT diagram, Fig. 1).

Patient characteristics are described in Table 1. 5676 $(51.2 \%)$ had single organ metastases. Median follow up $[95 \%$ CI] was 28.1 [26.7-29.5] months. At time of analysis $1742(15.7 \%)$ patients were alive and 5 were lost-to-follow-up. Bone was the most frequent metastatic site at diagnosis. Significantly more common in AdC than in SqCC were: bone $(43.0 \%$ versus $36.5 \%$, $p<0.001)$, brain $(22.0 \%$ versus $15.1 \%, p<0.001)$, pleura $(15.9 \%$ versus $12.6 \%, p<0.001)$ and lymph node metastases (only current M1b lymph nodes included) (11.6\% versus $10.1 \%, p=0.03$ ) (Fig. $2 \mathrm{~A}$ ).

Single organ metastases patients $(N=5676)$ were significantly older (mean age 66.1 versus 64.7 years, $p<0.001)$ and more often had SqCC $(31.0 \%$ versus $22.1 \%, p<0.001)$ and lower $\mathrm{TN}$-status $(18.3 \%$ versus
$9.8 \%, p<0.001$, Table 1$)$ than patients with $\geqslant 2$ organ metastases $(N=5418)$. In single organ metastases patients, bone $(28.7 \%$ versus $25.9 \%, p=0.031)$, brain $(21.4 \%$ versus $14.1 \%, p<0.001)$ and pleural metastases $(15.1 \%$ versus $11.9 \%, p=0.010)$ were significantly more common in $\mathrm{AdC}$ compared to $\mathrm{SqCC}$, liver $(7.7 \%$ versus $11.3 \%, p<0.001)$, adrenal $(7.1 \%$ versus $9.3 \%, p=$ $0.006)$, and lung metastases $(12.3 \%$ versus $18.2 \%, p<$ 0.001 ) were significantly less common in AdC (Fig. 2B).

\subsection{TNM6 and TNM7 overall survival}

Median OS for TNM6 $(N=4584)$ did not significantly differ from TNM7 M1b $(N=5091)$ (4.6 [4.4$4.8]$ versus 4.7 [4.4-4.9] months; $p=0.13)$. Median OS was significantly higher in TNM7 M1a $(N=1419)(8.3$ [7.6-9.0] months; $p<0.001)$ than in TNM6 and TNM7 M1b.

\subsection{Overall survival according to number of organs affected}

Median OS was significantly longer in single organ metastases patients $(N=5676)$ compared to patients with $2(N=3280)$ or $\geqslant 3$ organs with metastases $(N=2138)(6.7[6.4-7.0], 4.3[4.1-4.6]$, and $2.8[2.6-$ 3.0] months, respectively; $p<0.001$; Fig. 3A). In multivariate analysis this remained significant. HR $[95 \% \mathrm{CI}]$ for 2 organs versus 1 was $1.38[1.31-1.44](p<0.001)$ and $1.97[1.86-2.09]$ for $\geqslant 3$ organs versus 1 $(p<0.001)$. Other independent favourable factors for OS were younger age, female gender, AdC, TNM7 M1a and low TN-status (Suppl. Fig.4A).

In patients with a documented staging ${ }^{18}$ FDG-PETscan $(N=1517)$, OS was superior to that of the group in which it was not documented whether a staging ${ }^{18}$ FDG-PET-scan was performed $(N=9577)$. For the latter group, OS was 6.4 [6.1-6.7], 4.1 [3.9-4.4] and 2.7 [2.6-2.9] months $(\mathrm{p}<0.001)$ for single organ, 2 organs and $\geqslant 3$ organs with metastases, respectively. For the documented ${ }^{18}$ FDG-PET-scan group OS was 8.6 [7.99.4], 5.7 [5.0-6.4] and 3.8 [3.1-4.4] months, respectively; $p<0.001$, Fig. 3B). In multivariate analysis HR for 2 versus 1 organ(s) $\{1.40[1.23-1.60](p<0.001)\}$, and for $\geqslant 3$ versus $1 \operatorname{organ}(\mathrm{s})\{2.17[1.85-2.55](p<0.001)\}$ remained significant. Other independent favourable factors for OS were identical to those for no documented ${ }^{18}$ FDG-PET-scan group (Suppl. Fig. 4B).

\subsection{Overall survival in single organ metastases patients according to local disease status and impact of specific organ affected}

Median OS was significantly higher in patients with low TN-status $(N=1043)$ and was 8.5 [7.6-9.3] months compared to $6.5[6.2-6.8]$ months for high TN-status 


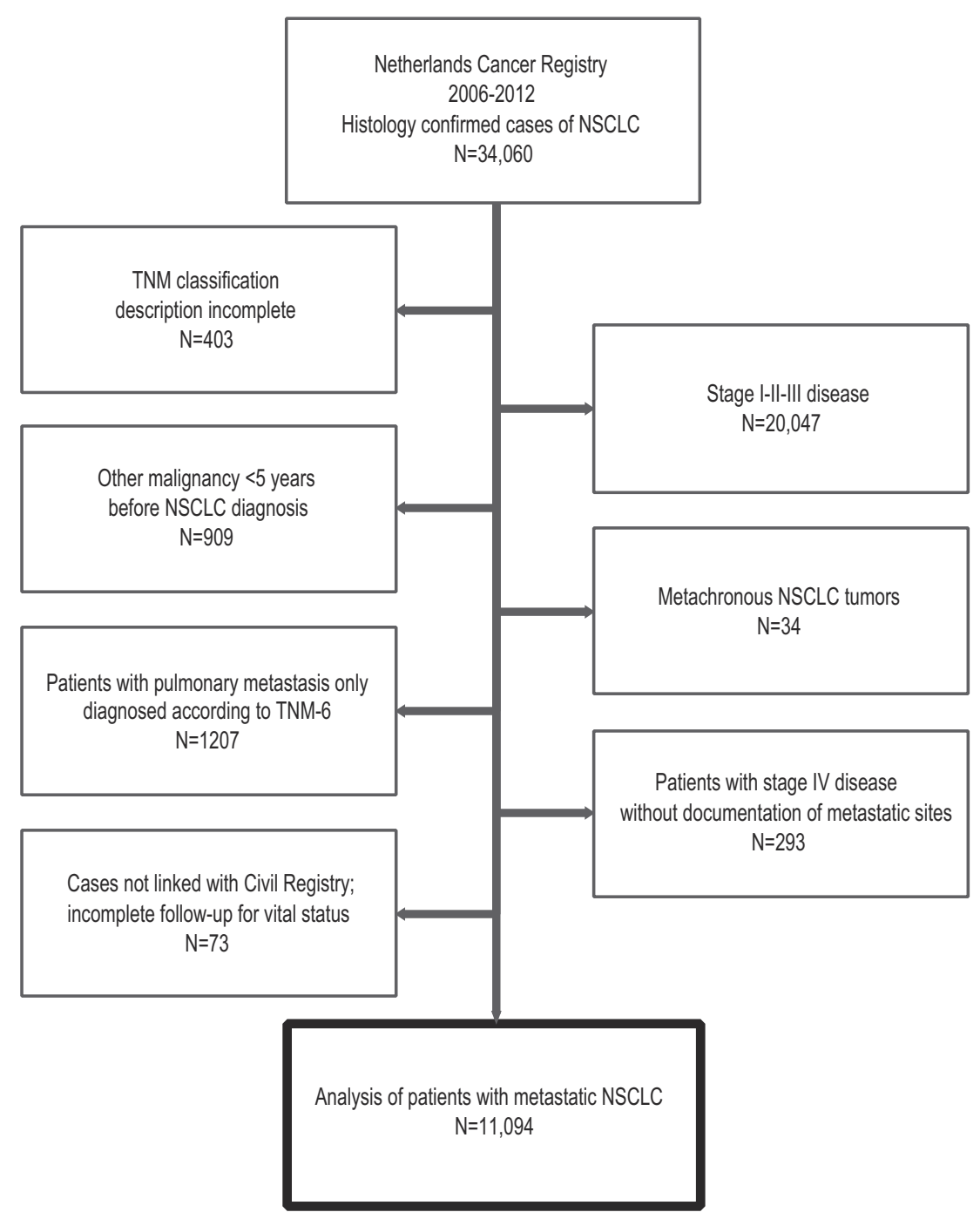

Fig. 1. CONSORT diagram presenting the selection of stage IV NSCLC patients between 2006 and 2012 from the Netherlands Cancer Registry database. Abbreviation: NSCLC: non-small cell lung cancer.

$(N=4375)(p<0.001$, Fig. 5A). In multivariate analysis, this retained its prognostic value: high versus low TN-status HR 1.40 [1.29-1.51] $(p<0.001)$. Other independent favourable factors were younger age, female gender, and AdC. Liver metastases were an unfavourable prognostic factor, whereas adrenal, pulmonary and pleural disease as well as lymph node metastases were favourable factors (Fig. 6A).

When TNM6 $(N=2089)$ and TNM7 $(N=3587)$ classified patients were analysed separately, low $\mathrm{TN}$-status had a superior median OS compared to high TN-status in both TNM6 $(7.5[6.2-8.8]$ versus 5.8 [5.3-6.2] months, respectively; $p<0.001)$ and TNM7 (9.6 [8.3-10.8] versus 7.0 [6.5-7.4] months, respectively; $p<0.001)$.

Patients with documented ${ }^{18}$ FDG-PET-scans $(N=848)$ had superior OS compared to the total single organ metastases group $(p<0.001)$. Median OS differences for low versus high $\mathrm{TN}$-status remained significant (11.6 [8.1-15.1] months and 8.2 [7.3-9.1] months, respectively; $p<0.001$, Fig. 5B). In multivariate analysis, $\mathrm{TN}$-status remained of prognostic significance (high versus low TN-status: HR 1.62 [1.31-1.99], $p<0.001)$. Other independent favourable factors were younger age and female gender. Metastatic disease in the brain, lungs, pleura or lymph nodes was a favourable prognostic factor (Fig. 6B).

When TNM6 and TNM7 classified patients were analysed separately, median OS for TNM6 low TN-status $(N=81)$ was 12.5 [8.4-16.5] months compared to 7.0 [6.2-7.8] months for high TN-status $(N=300)$ $(p<0.001)$. For TNM7 median OS was 10.1 [5.6-14.6] months for low $(N=83)$ and 9.7 [8.1-11.2] months for high TN-status $(N=357)(p=0.121)$. 
Table 1

patient characteristics stage IV non-small cell lung cancer (NSCLC) and subgroup of single organ metastases.

\begin{tabular}{|c|c|c|c|c|c|c|}
\hline \multirow{2}{*}{$\begin{array}{l}\text { Patient characteristic } \\
\text { Subgroup }\end{array}$} & \multicolumn{3}{|l|}{ Total group } & \multicolumn{3}{|c|}{ Single organ metastases } \\
\hline & Total & AdC & $\mathrm{SqCC}$ & Total & AdC & $\mathrm{SqCC}$ \\
\hline Patient number $(N)$ & 11,094 & 8134 & 2960 & 5676 & 3915 & 1761 \\
\hline Age (years) Mean \pm SD & $65.4 \pm 10.7$ & $64.2 \pm 10.8$ & $68.7 \pm 9.9$ & $66.1 \pm 10.8$ & $64.7 \pm 10.9$ & $69.2 \pm 9.9$ \\
\hline \multicolumn{7}{|l|}{ Categories $(N(\%))$} \\
\hline$<50$ years & 877 (7.9) & $775(9.5)$ & $102(3.4)$ & $419(7.4)$ & $359(9.2)$ & $60(3.4)$ \\
\hline$\geqslant 50$ and $<60$ years & $2325(21.0)$ & $1904(23.4)$ & $421(14.2)$ & $1113(19.6)$ & $881(22.5)$ & $232(13.2)$ \\
\hline$\geqslant 60$ and $<70$ years & $3721(33.5)$ & $2767(34.0)$ & $954(32.2)$ & $1836(32.3)$ & $1289(32.9)$ & $547(31.1)$ \\
\hline$\geqslant 70$ & $4171(37.6)$ & $2688(33.0)$ & $1483(50.1)$ & $2308(40.7)$ & $1386(35.4)$ & $922(52.4)$ \\
\hline \multicolumn{7}{|l|}{ Gender $(N(\%))$} \\
\hline Male & $6625(59.7)$ & $4464(54.9)$ & $2171(73.0)$ & $3389(59.7)$ & $2089(53.4)$ & $1300(73.8)$ \\
\hline \multicolumn{7}{|l|}{ T-stage $(N(\%))$} \\
\hline TNMG & $4584(100.0)$ & $3321(100.0)$ & $1263(100.0)$ & $2089(100.0)$ & $1433(100.0)$ & $656(100.0)$ \\
\hline $0 / \mathrm{X}$ & $525(11.5)$ & $417(12.6)$ & $108(8.6)$ & $244(11.7)$ & $194(13.5)$ & $50(7.6)$ \\
\hline 1 & $481(10.5)$ & $417(12.6)$ & $64(5.1)$ & $270(12.9)$ & $231(16.1)$ & $39(5.9)$ \\
\hline 2 & $1476(32.2)$ & $1025(30.9)$ & $451(35.7)$ & 729 (34.9) & $464(32.4)$ & $265(40.4)$ \\
\hline 3 & $314(6.8)$ & $186(5.5)$ & $128(10.1)$ & $164(7.9)$ & $100(7.0)$ & $64(9.8)$ \\
\hline 4 & $1788(39.0)$ & $1276(38.4)$ & $512(40.5)$ & $682(32.6)$ & $444(31.0)$ & $238(36.3)$ \\
\hline$T N M 7$ & $6510(100.0)$ & $4813(100.0)$ & $1697(100.0)$ & $3587(100.0)$ & $2482(100.0)$ & $1105(100.0)$ \\
\hline $0 / \mathrm{X}$ & $608(9.3)$ & 509 (10.6) & $99(5.8)$ & $338(9.4)$ & $283(11.4)$ & $55(5.0)$ \\
\hline 1a & $312(4.8)$ & $285(5.9)$ & 27 (1.6) & $186(5.2)$ & $167(6.7)$ & $19(1.7)$ \\
\hline $1 b$ & 383 (5.9) & $330(6.9)$ & $53(3.1)$ & $237(6.6)$ & $196(7.9)$ & $41(3.7)$ \\
\hline $2 \mathrm{a}$ & $1205(18.5)$ & $910(18.9)$ & $295(17.4)$ & $718(20.0)$ & $509(20.5)$ & 209 (18.9) \\
\hline $2 b$ & $439(6.7)$ & $305(6.3)$ & $134(7.9)$ & $257(7.2)$ & $161(6.5)$ & $96(8.7)$ \\
\hline 3 & $1257(19.3)$ & 851 (17.7) & $406(23.9)$ & $727(20.3)$ & $467(18.8)$ & $260(23.5)$ \\
\hline 4 & $2306(35.5)$ & $1623(33.7)$ & $683(40.3)$ & $1124(31.3)$ & 699 (28.2) & $425(38.5)$ \\
\hline \multicolumn{7}{|l|}{ N-stage $(N(\%))$} \\
\hline $0 / \mathrm{X}$ & $2769(25.0)$ & $2036(25.0)$ & $733(24.8)$ & $1733(30.5)$ & $1250(31.9)$ & 483 (27.4) \\
\hline 1 & $732(6.6)$ & 527 (6.5) & $205(6.9)$ & $421(7.4)$ & $292(7.5)$ & $129(7.3)$ \\
\hline 2 & $4418(39.8)$ & $3138(38.6)$ & $1280(43.2)$ & $2155(38.0)$ & $1403(35.8)$ & $752(42.7)$ \\
\hline 3 & 3175 (28.6) & 2433 (29.9) & $742(25.1)$ & $1367(24.1)$ & $970(24.8)$ & $397(22.5)$ \\
\hline \multicolumn{7}{|l|}{ M-stage (N (\%)) } \\
\hline \multicolumn{7}{|l|}{ TNM6 } \\
\hline 1 & $4584(100.0)$ & $3321(100.0)$ & $1263(100.0)$ & $2089(100.0)$ & $1433(100.0)$ & $656(100.0)$ \\
\hline TNM7 & $6500(100.0)$ & $4813(100.0)$ & $1697(100.0)$ & $3587(100.0)$ & $2482(100.0)$ & $1105(100.0)$ \\
\hline 1a & $1419(21.8)$ & 957 (19.9) & $462(27.2)$ & $1323(36.9)$ & $872(35.1)$ & $451(40.8)$ \\
\hline $1 b$ & $5091(78.2)$ & $3856(80.1)$ & $1235(72.8)$ & $2264(63.1)$ & $1610(64.9)$ & $654(59.2)$ \\
\hline \multicolumn{7}{|c|}{ Number of organs with metastases $(N(\%))$} \\
\hline 1 & $5676(51.2)$ & $3859(47.4)$ & $1761(59.5)$ & N/A & N/A & N/A \\
\hline 2 & $3280(29.6)$ & $2480(30.5)$ & $798(27.0)$ & & & \\
\hline$\geqslant 3$ & $2138(19.3)$ & $1795(22.1)$ & $401(13.5)$ & & & \\
\hline
\end{tabular}

Abbreviations: TNM: tumour, node, metastasis; $N$ : number; SD: standard deviation; AdC: adenocarcinoma; SqCC: squamous cell carcinoma; N/A: not applicable.

\subsection{Subgroup of patients receiving active anticancer treatment}

Patients receiving active anticancer treatment $(N=6022)$ had a superior median OS compared to the BSC group (median 8.4 versus 2.2 months, $p<0.001$ ).

Single organ metastases patients $(N=3206)$ had a significantly superior OS compared to patients with 2 $(N=1791)$ or $\geqslant 3$ organs $(N=1025)$ involved. Median
OS was 10.4 [10.0-10.8], 7.3 [7.0-7.7] and 5.7 [5.3-6.1] months, respectively $(p<0.001$, Suppl. Fig. 7A). For the ${ }^{18}$ FDG-PET-staged subgroup this was 11.7 [10.5-12.9], 8.1 [7.2-9.0] and 6.4 [5.2-7.6] months, respectively $(p<0.001)$.

Single organ metastases patients with low TN-status $(N=547)$ had significantly higher median OS compared to high TN-status $(N=2581): 13.7[12.5-14.9]$ versus 9.9 [9.4-10.3] months, respectively $(p<0.001$, Suppl. 


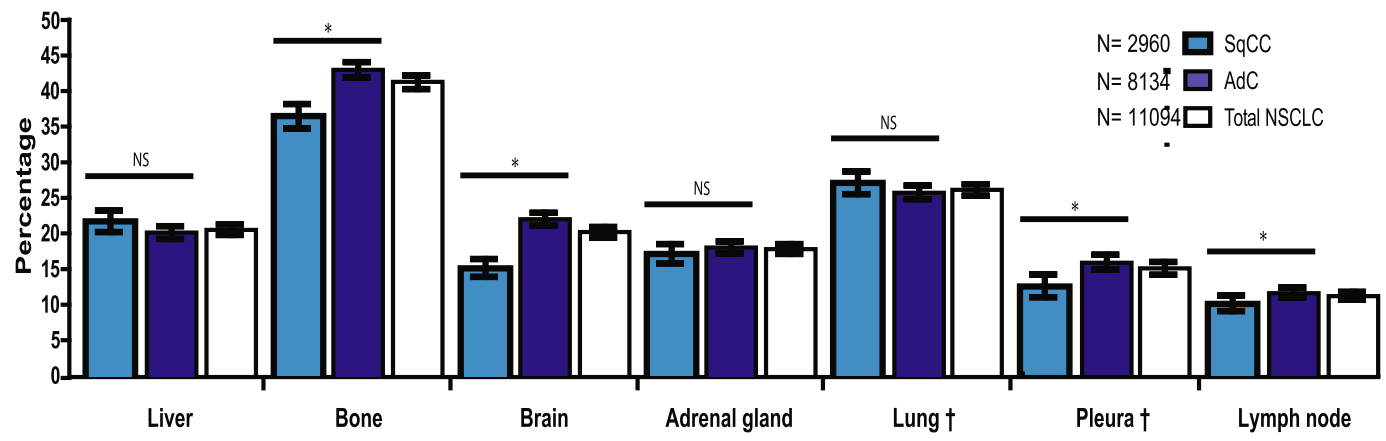

Fig. 2A. Prevalence of actual organ with metastases in the total group, and the AdC and SqCC subgroups (one patient can have more than one organ metastase). AdC is compared with SqCC. Abbreviations: AdC: adenocarcinoma; SqCC: squamous cell carcinoma.

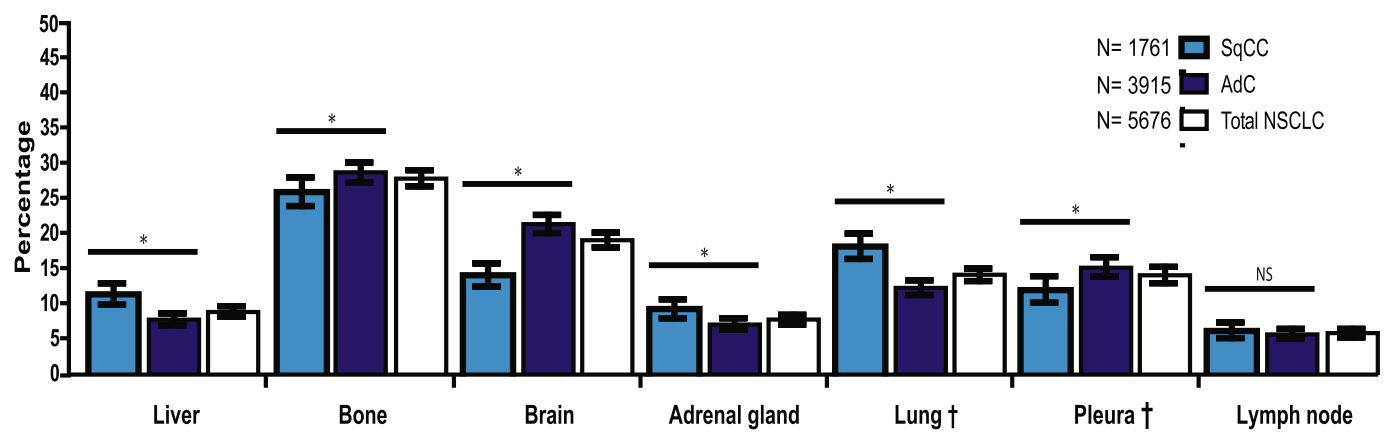

Fig. 2B. Prevalence of actual organ with metastases in the single organ metastases group, and the AdC and SqCC subgroups. AdC is compared with SqCC. ${ }^{\dagger}$ : Analysed only in TNM7; *: Significant, $p<0.05$ Chi-square test. Abbreviations: N: number; NSCLC: non-small cell lung cancer; AdC: adenocarcinoma; SqCC: squamous cell carcinoma.

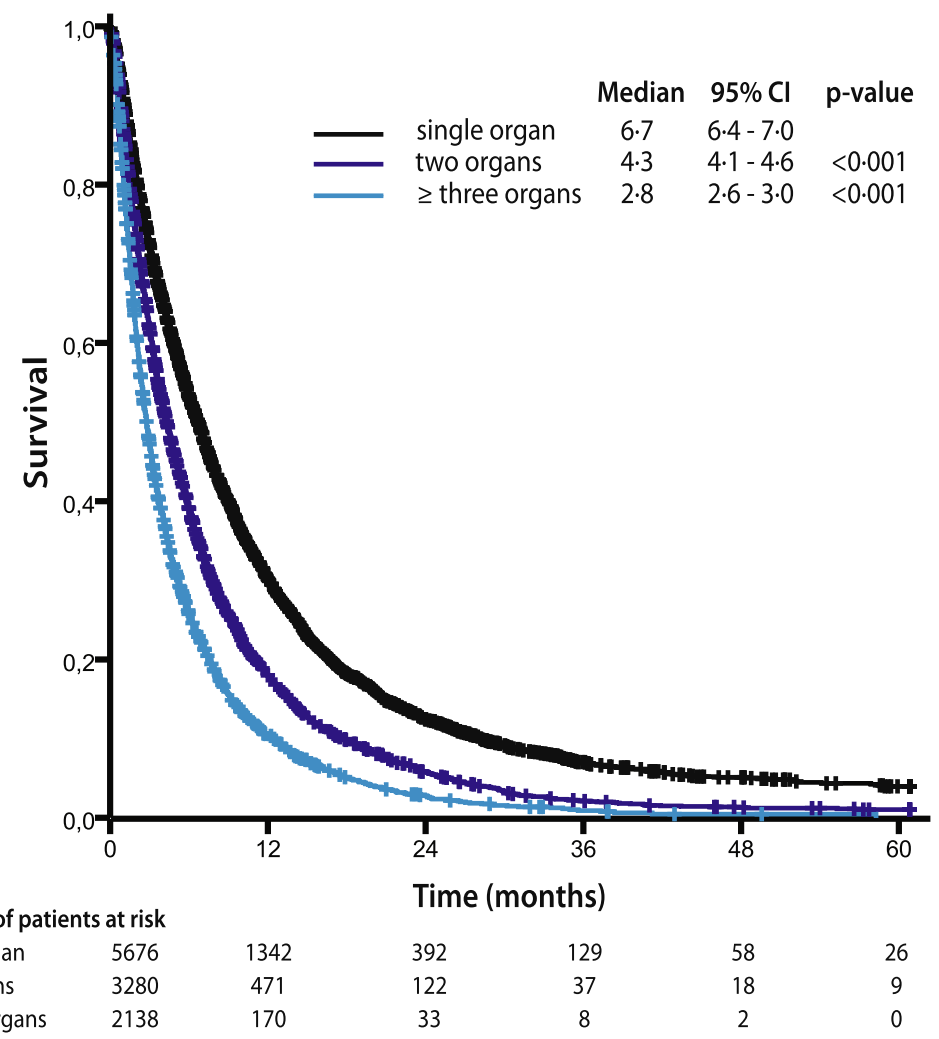

Fig. 3A. Kaplan-Meier curves for the overall cohort according to number of organs with metastases $(1,2$, and $\geqslant 3)$. 


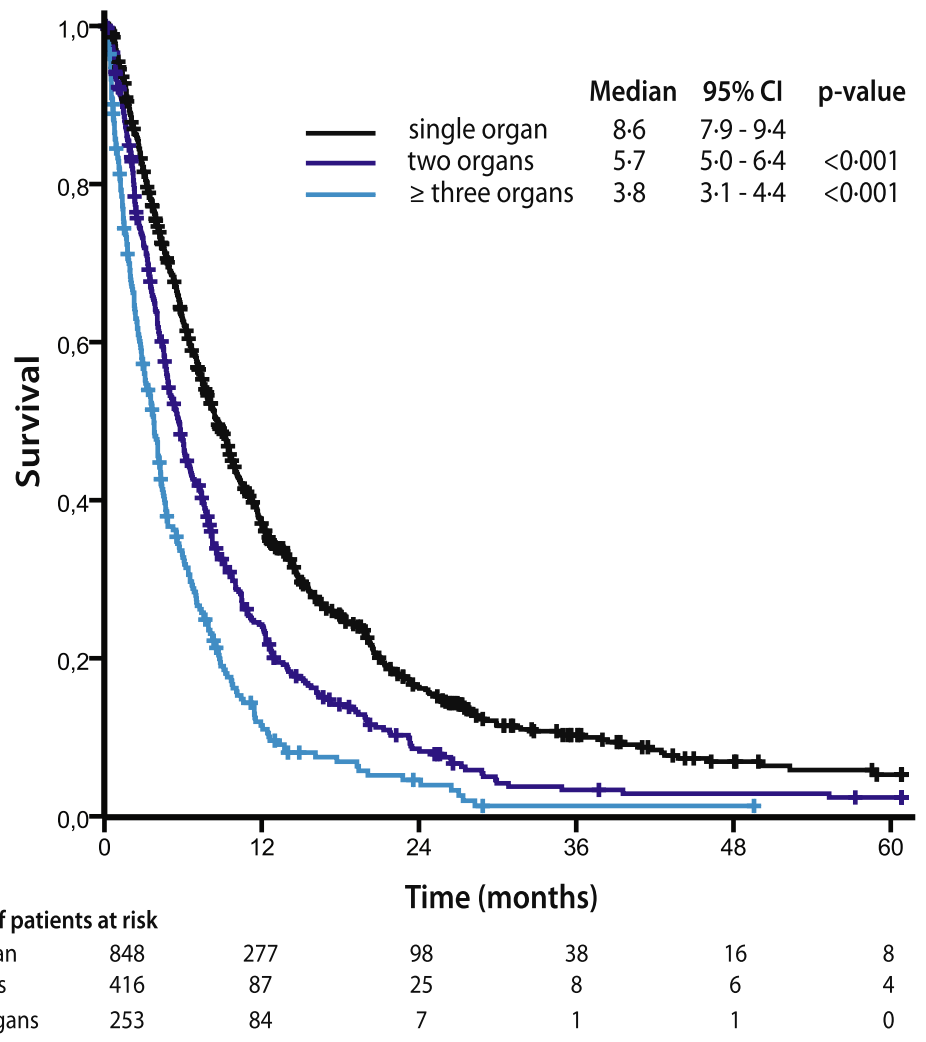

Fig. 3B. Kaplan-Meier curves for the ${ }^{18}$ fluorodeoxyglucose-positron emission tomography $\left({ }^{18}\right.$ FDG-PET)-staged subgroup according to number of organs with metastases $(1,2$, and $\geqslant 3)$.

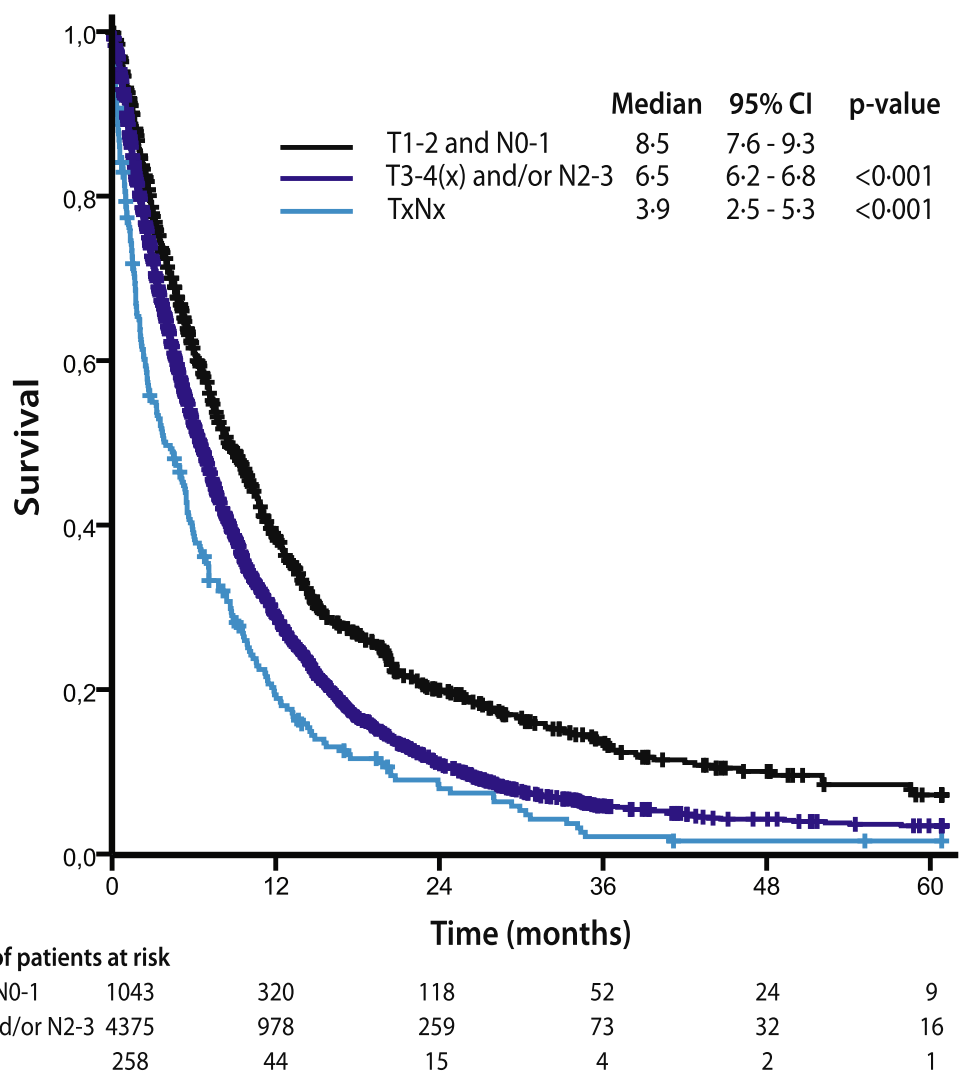

Fig. 5A. Kaplan-Meier curves for the single organ metastases group according to local disease status. 


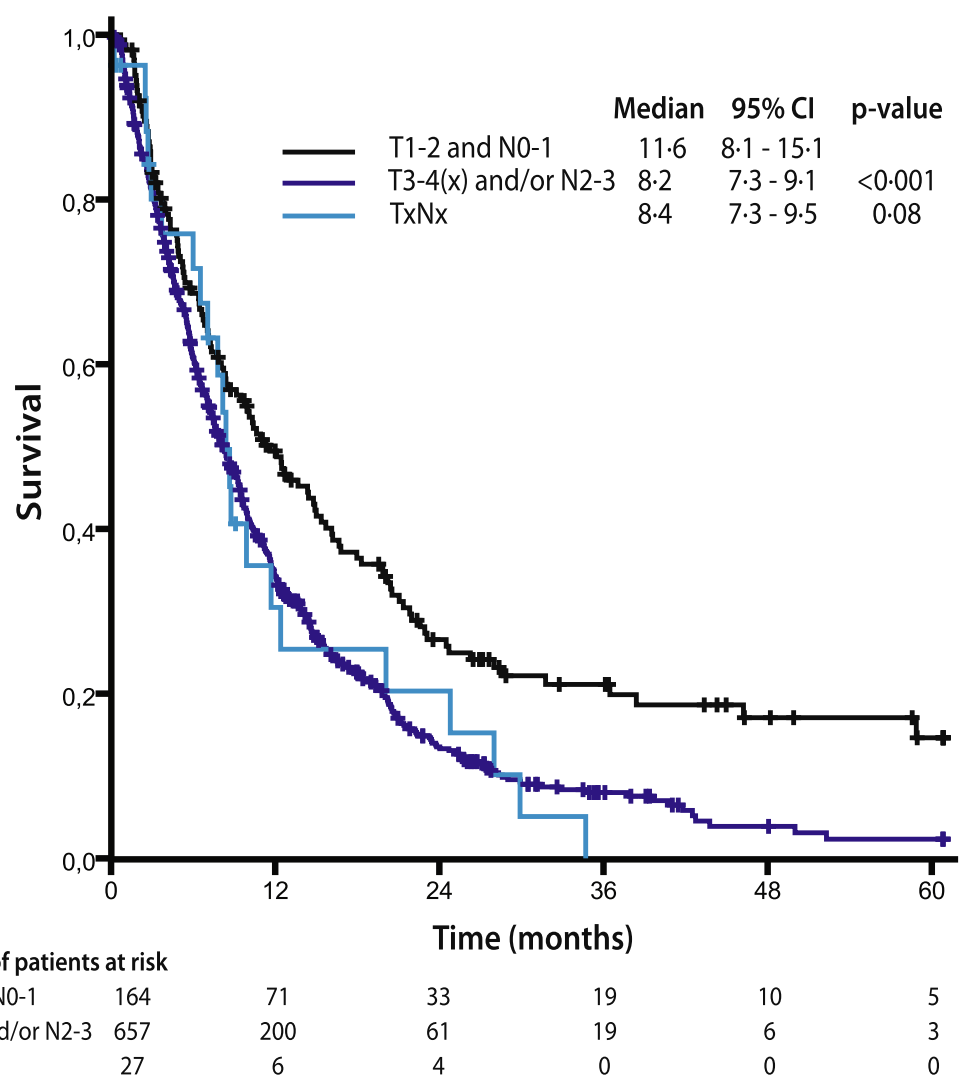

Fig. 5B. Kaplan-Meier curves for the single organ metastases ${ }^{18}$ fluorodeoxyglucose-positron emission tomography $\left({ }^{18}\right.$ FDG-PET)-staged subgroup according to local disease status. Abbreviations: T: tumour; N: node; CI: confidence interval.

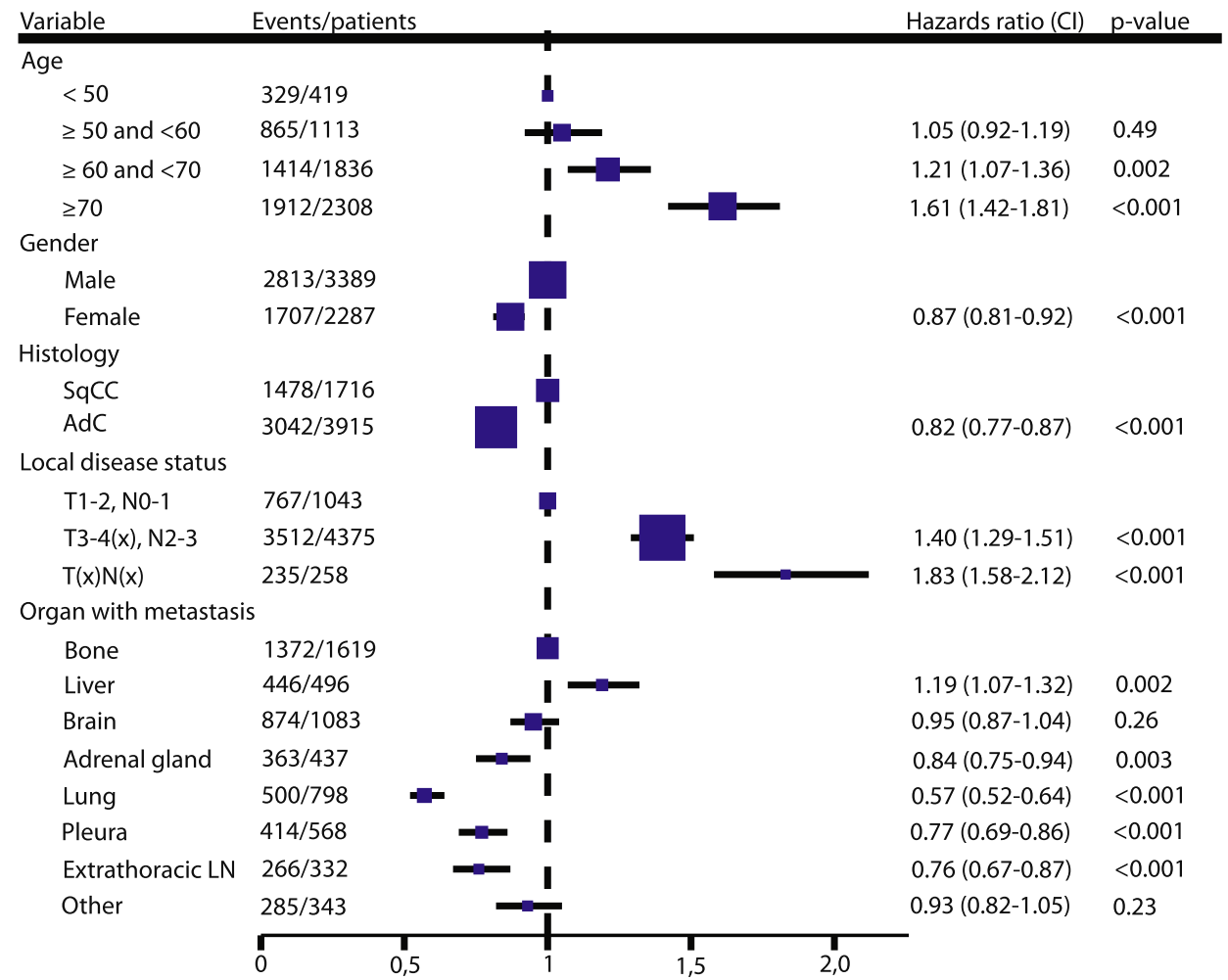

Fig. 6A. Forest plot showing prognostic factors in multivariate analyses for the single organ metastases group. 


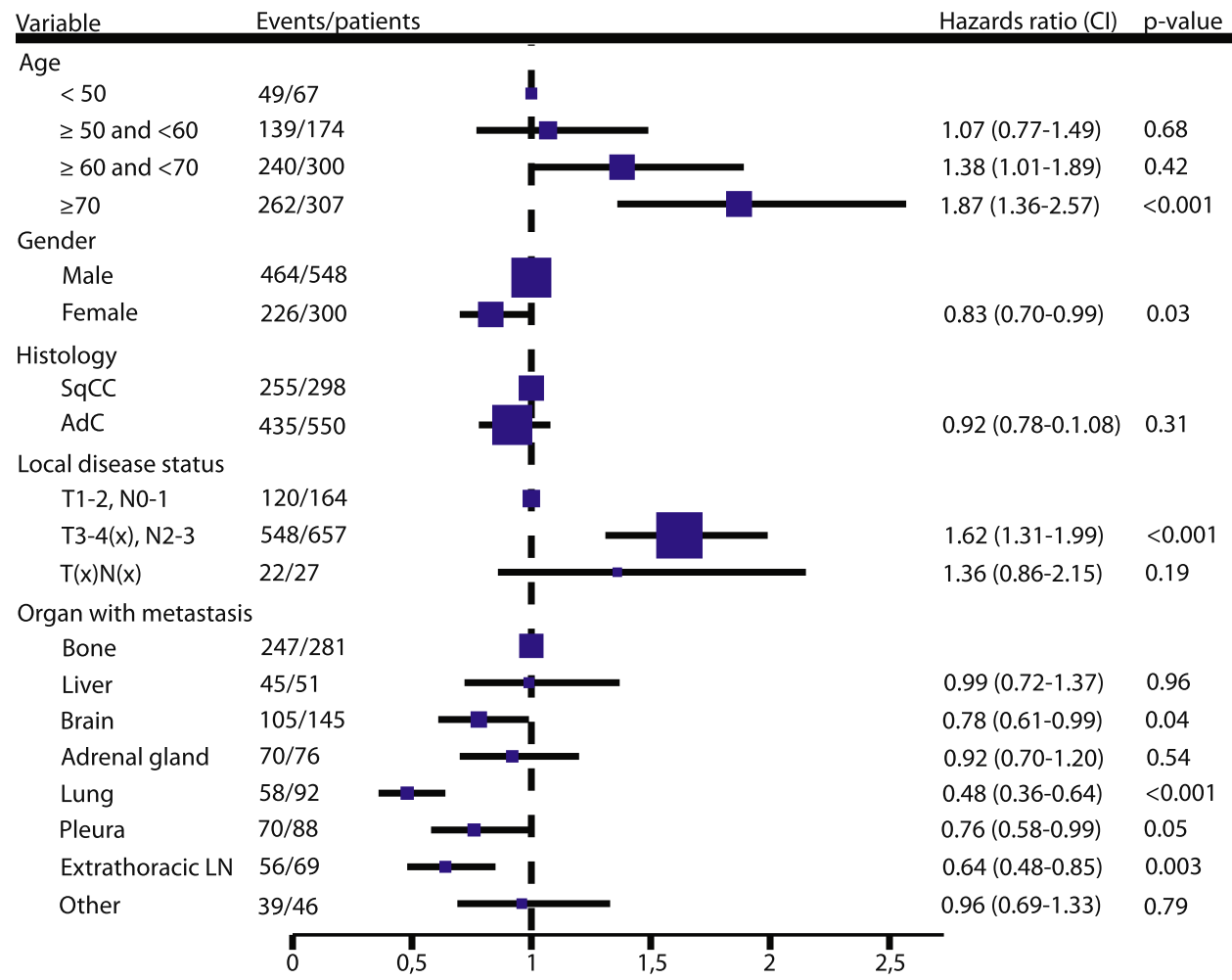

Fig. 6B. Forest plot showing prognostic factors in multivariate analyses for the ${ }^{18}$ fluorodeoxyglucose-positron emission tomography $\left({ }^{18}\right.$ FDG-PET)-staged subgroup in the single organ metastases group. Abbreviations: T: tumour; N: node; M: metastases; CI: confidence interval; LN: lymph node.

Fig. 7B). For the ${ }^{18}$ FDG-PET-staged subgroup this was $14.4[11.2-17.5]$ and $9.2[8.6-9.8]$ months, respectively $(p<0.001)$.

\section{Discussion}

In this large population-based study NSCLC patients with single organ metastases, in particular with low TN-status, had a superior median OS compared to those with multiple organs with metastases. These results add to results obtained by Albain et al. [6] $(N=2531$, retrospective multicentre study), Jeremic et al. [7] $(N=285$, retrospective single centre study), Sanchez de Cos Esquin et al. [8] $\left(N=640\left(18 \%{ }^{18}\right.\right.$ FDG-PET staged $)$, prospective observational multiregional study), $\mathrm{Oh}$ et al. [9] ( $N=1284$, retrospective single centre study), Paralkar et al. $[10]\left(N=172\left(10 \%{ }^{18}\right.\right.$ FDG-PET staged $)$, retrospective single tertiary centre study), Pirker et al. [11] $(N=1125$, FLEX study: chemotherapy with/without cetuximab) and Parikh et al. [12] $(N=186$, prospective single centre study including only oligometastatic ${ }^{18}$ FDG-PET-staged NSCLC patients). However, compared to these studies, our study is population-based and includes the largest ${ }^{18}$ FDG-PET staged subgroup $(N=1517)$. Also in this subgroup the same prognostic factors were found.

In all previously reported studies, patients with single organ metastases had a better prognosis than those with metastasis to more than one organ. Only in one study impact of $\mathrm{N}$-status was evaluated: patients with $\mathrm{N} 0-1$ disease had better outcome [12]. In two other studies $(N=67,149$ and $N=850) \mathrm{N}$-status was evaluated, in one in the current M1a group only $[13,14]$. Nodal disease was a negative prognostic factor. However, the number of metastatic sites was not (extensively) evaluated $[13,14]$. Other favourable prognostic factors for OS found in our study (female gender, AdC, intrapulmonary metastases) were also identified in other studies [6,8,12,15-17].

Potential explanations for better OS in single organ metastases patients is that smaller tumour load contributes to longer survival, or that the disease is found in an earlier stage, i.e. lead time bias [18].

It is suggested that patients with single or oligometastatic brain metastases or adrenal gland metastases have a favourable prognosis with reported median OS of 1231 months $[15,19,20]$. In our study, patients with single organ brain or adrenal metastases did not persistently have better OS compared to patients with other organs affected. A possible explanation for the lack of survival advantage in the brain metastases group is that we were not able to differentiate between single, oligo- and multiple brain metastases. In addition, for both the brain and adrenal glands data collected in the NCR do not allow for differentiation between radical versus palliative local treatment.

Local disease status was another prognostic factor for OS. In this context a recently developed Markov 
chain/Monte Carlo stochastic mathematical model for cancer progression is of interest [21]. In this model, cancer progression is regarded as a multidirectional process instead of the commonly accepted unidirectional cancer progression (i.e. initiated at the primary tumour and stepwise progression to distant metastatic sites). For lung cancer, three types of tumour seeding were proposed: primary tumour self-seeding, metastatic location to primary tumour reseeding and metastasis reseeding with the most important metastatic pathway being lung to regional lymph nodes and adrenals. Furthermore, lymph nodes (and adrenals) were considered active reseeders promoting dissemination. One can imagine that in this model low TN-status represents a tumour behaving less aggressively [21]. Another possibility is that patients with bulky central thoracic disease die sooner because of respiratory complications [22].

As patients with single organ metastases and low TNstatus had the highest OS, it is tempting to speculate whether a subgroup of these patients would achieve an even better OS when treated radically. Radical treatment is often aimed at in patients with oligometastases in the brain or adrenal(s). However, it is not clear whether these patients by nature have a superior OS or that OS can be improved with radical treatment, as was also discussed in a recent review [23].

A strong aspect of this study is that it is based on a population-based registry with over $98 \%$ case ascertainment [4]. Data were collected by trained data managers including an extensive evaluation of $\mathrm{TN}$-status, site specific metastases and first line treatment. Moreover, the same prognostic factors were found in the ${ }^{18} \mathrm{FDG}$ PET-staged subgroup and in the $\left({ }^{18}\right.$ FDG-PET-staged $)$ active treatment subgroup.

Limitations are that although data were prospectively collected this was a retrospective analysis. Some established prognostic factors (performance status, smoking status, comorbidities), which may have influenced reported data, were not recorded in the registry. Also, only first line treatment was recorded. Second, median OS in this dataset is lower than usually reported in clinical trials reflecting the outcome of the general population. Third, the effect of ${ }^{18}$ FDG-PET-scanning could only be evaluated in a subset of patients. Fourth, under-diagnosis of brain metastases may have occurred for brain imaging has not been mandatory in the stage IV NSCLC workup. Fifth, as in other published studies [8,15-17], patients reported here with intrapulmonary metastases only have a relatively good prognosis. A caveat is that some of these may in fact have two primary tumours and were thus misclassified as stage IV. However, this study reflects daily practice and these patients were regarded stage IV. Moreover, when we repeated all analyses performed excluding these patients results remained comparable. Sixth, data regarding mutation analysis (e.g. EGFR) were not available.
However, as percentage of non-squamous NSCLC patients with an activating $E G F R$-mutation is approximately $9 \%$ in the Dutch population, and the percentage of other targetable mutations or translocations is even lower, it is not likely that this has influenced our results $[24,25]$. Seventh, the definition for the low versus high TN-groups is arbitrary, especially whether N1 should be included in the low TN-group. However, when the multivariate analyses were repeated with $\mathrm{N} 0$ and $\mathrm{N} 1$ as separate groups, prognosis for the $\mathrm{N} 1$ group was not significantly different from the N0 group (data not shown). Finally, for the TNM classification slightly changed in the 7th edition, these changes might have influenced our results. Data to recode TNM6 into TNM7 were not available. However, results did not change significantly when we analysed TNM6 and 7 separately.

In conclusion, this hypothesis generating study shows that stage IV NSCLC patients with single organ metastases have a favourable prognosis, especially in combination with a low TN-status. Recently, the IASLC has started with the prospective collection of more detailed patient data in order to refine the TNM7 [26]. It would be of interest to validate our results in this dataset, as data regarding number of (organs with) metastases are collected for the new TNM classification. We suggest that, besides the already existing Mla category, patients in the M1b category are subdivided according to one versus more organs with metastases, as the largest difference in OS is found between one and two organs with metastases. If validated, this should also be considered as a stratification factor in clinical trials.

\section{Funding/support}

\section{None.}

\section{Conflict of interest statement}

P. Postmus: board membership: Boehringer Ingelheim, Celgene, Clovis Oncology, Halozyme and Teva. Consultancy: Celgene Speakers' bureau: Eli Lilly. Payment for manuscript preparation: GSK.

A. Dingemans has a consulting or advisory role for Roche, Eli Lilly, Boehringer Ingelheim, Pfizer, Novartis, BMS, MSD. Speakers' bureau: Roche.

R. Damhuis received payment for lectures from Eli Lilly and received travel fees from Pfizer.

The remaining authors have no conflict of interest to declare.

\section{Appendix A. Supplementary data}

Supplementary data associated with this article can be found, in the online version, at http://dx.doi.org/10. 1016/j.ejca.2015.08.008. 


\section{References}

[1] Groome PA, Bolejack V, Crowley JJ, et al. The IASLC Lung Cancer Staging Project: validation of the proposals for revision of the $\mathrm{T}, \mathrm{N}$, and $\mathrm{M}$ descriptors and consequent stage groupings in the forthcoming (seventh) edition of the TNM classification of malignant tumours. J Thoracic Oncol 2007;2:694-705.

[2] Postmus PE, Brambilla E, Chansky K, et al. The IASLC Lung Cancer Staging Project: proposals for revision of the M descriptors in the forthcoming (seventh) edition of the TNM classification of lung cancer. J Thoracic Oncol 2007;2:686-93.

[3] Dinan MA, Curtis LH, Carpenter WR, et al. Stage migration, selection bias, and survival associated with the adoption of positron emission tomography among medicare beneficiaries with non-small-cell lung cancer, 1998-2003. J Clin Oncol 2012;30:2725-30.

[4] Visser OSS, van Dijck JAAM, editors. Incidence of cancer in the Netherlands 1999/2000, eleventh report of the Netherlands Cancer Registry. The Netherlands Cancer Registry (NCR), Vereniging van Integrale Kankercentra; 2003.

[5] Rossi G, Mengoli MC, Cavazza A, et al. Large cell carcinoma of the lung: clinically oriented classification integrating immunohistochemistry and molecular biology. Virchows Archiv 2014;464:61-8.

[6] Albain KS, Crowley JJ, LeBlanc M, et al. Survival determinants in extensive-stage non-small-cell lung cancer: the Southwest Oncology Group experience. J Clin Oncol 1991;9:1618-26.

[7] Jeremic B, Milicic B, Dagovic A, et al. Pretreatment clinical prognostic factors in patients with stage IV non-small cell lung cancer (NSCLC) treated with chemotherapy. J Cancer Res Clin Oncol 2003;129:114-22.

[8] Sanchez de Cos Escuin J, Abal Arca J, Melchor Iniguez R, et al. Tumor, node and metastasis classification of lung cancer-Mla versus M1b-analysis of $\mathrm{M}$ descriptors and other prognostic factors. Lung Cancer 2014;84:182-9.

[9] Oh Y, Taylor S, Bekele BN, et al. Number of metastatic sites is a strong predictor of survival in patients with nonsmall cell lung cancer with or without brain metastases. Cancer 2009;115:2930-8.

[10] Paralkar VR, Li T, Langer CJ. Population characteristics and prognostic factors in metastatic non-small-cell lung cancer: a Fox Chase Cancer Center retrospective. Clin. Lung Cancer 2008;9:116-21.

[11] Pirker R, Pereira JR, Szczesna A, et al. Prognostic factors in patients with advanced non-small cell lung cancer: data from the phase III FLEX study. Lung Cancer 2012;77:376-82.

[12] Parikh RB, Cronin AM, Kozono DE, et al. Definitive primary therapy in patients presenting with oligometastatic non-small cell lung cancer. Int J Radiat Oncol Biol Phys 2014;89:880-7.
[13] William Jr WN, Lin HY, Lee JJ, et al. Revisiting stage IIIB and IV non-small cell lung cancer: analysis of the surveillance, epidemiology, and end results data. Chest 2009;136:701-9.

[14] Hoang T, Dahlberg SE, Sandler AB, et al. Prognostic models to predict survival in non-small-cell lung cancer patients treated with first-line paclitaxel and carboplatin with or without bevacizumab. J Thoracic Oncol 2012;7:1361-8.

[15] Collaud S, Stahel R, Inci I, et al. Survival of patients treated surgically for synchronous single-organ metastatic NSCLC and advanced pathologic TN stage. Lung Cancer 2012;78:234-8.

[16] Peng H, Ma M, Han B. [Survival analysis of 1,742 patients with stage IV non-small cell lung cancer]. Zhongguo Fei Ai Za Zhi 2011;14:362-6.

[17] Tonnies M, Pfannschmidt J, Bauer TT, et al. Metastasectomy for synchronous solitary non-small cell lung cancer metastases. Ann Thoracic Surg 2014;98:249-56.

[18] Liao S, Penney BC, Zhang H, et al. Prognostic value of the quantitative metabolic volumetric measurement on $18 \mathrm{~F}-\mathrm{FDG}$ $\mathrm{PET} / \mathrm{CT}$ in Stage IV nonsurgical small-cell lung cancer. Acad Radiol 2012;19:69-77.

[19] Maclean J, Fersht N, Singhera M, et al. Multi-disciplinary management for patients with oligometastases to the brain: results of a 5 year cohort study. Radiat Oncol 2013;8:156.

[20] Gray PJ, Mak RH, Yeap BY, et al. Aggressive therapy for patients with non-small cell lung carcinoma and synchronous brain-only oligometastatic disease is associated with long-term survival. Lung Cancer 2014;85:239-44.

[21] Newton PK, Mason J, Bethel K, et al. Spreaders and sponges define metastasis in lung cancer: a Markov chain Monte Carlo mathematical model. Cancer Res 2013;73:2760-9.

[22] Higginson DS, Chen RC, Tracton G, et al. The impact of local and regional disease extent on overall survival in patients with advanced stage IIIB/IV non-small cell lung carcinoma. Int J Radiat Oncol Biol Phys 2012;84:e385-392.

[23] Palma DA, Salama JK, Lo SS, et al. The oligometastatic stateseparating truth from wishful thinking. Nat Rev Clin Oncol 2014.

[24] Sequist LV, Heist RS, Shaw AT, et al. Implementing multiplexed genotyping of non-small-cell lung cancers into routine clinical practice. Ann Oncol 2011;22:2616-24.

[25] Kerner GS, Schuuring E, Sietsma J, et al. Common and rare EGFR and KRAS mutations in a Dutch non-small-cell lung cancer population and their clinical outcome. PLoS One 2013;8: e70346.

[26] Rami-Porta R, Bolejack V, Giroux DJ, et al. The IASLC lung cancer staging project: the new database to inform the eighth edition of the TNM classification of lung cancer. J Thoracic Oncol 2014;9:1618-24. 